\title{
Directing Regenerative Medicine through Precise Gene-editing Technology
}

\author{
Cota-Coronado Agustin and Diaz-Martinez Emmanuel* \\ Medical and Pharmaceutical Biotechnology, Center for Research and Assistance in Technology and Design of the State of Jalisco (CIATEJ), Mexico
}

Submission: November 01, 2018; Published: November 27, 2018

*Corresponding author: Diaz-Martinez Emmanuel, Medical and Pharmaceutical Biotechnology, Center for Research and Assistance in Technology and Design of the State of Jalisco (CIATEJ), A.C. AP 44270, Guadalajara, Jalisco, Mexico

\begin{abstract}
Regenerative medicine, an emerging area of health, is currently being explored in depth and could have a tremendous impact on improving the quality of life of the world's population. The study of molecular mechanisms of Stem Cells has evidenced its regenerative properties, at the same time, the maturation of the precise gene-editing technology (CRISPR/Cas9), has made it possible to manipulate key regenerative properties such as self-renewal and the controlled release of trophic factors, allowing to improve the natural regenerative process in situ, among mammalian organisms.
\end{abstract}

Keywords: CRISPR/Cas9; Stem cells; Gene-editing; Trophic factors; Secretome; D-Cas9

\section{Introduction}

Regenerative medicine is currently taking a tremendously interesting course; derived from the depth of molecular studies of stem cells and tissue organization. Therefore; the CRISPR/ Cas9 systems; has been proven to be a powerful tool for precise genome targeting; becoming a multiple "swiss-knife" that allows the manipulation of human Stem Cells in many ways. Thus; while different versions of the initial SpCas9 (from Streptococcus pyogenes) have been developed; many groups have manipulated Stem cells [1]; seeking to improvement of regenerative properties in vitro and in situ.

Henceforth recent years; three types of stem cells have seized the international scene for their capacities; Embryonic Stem Cells (ESCs); Induced Pluripotent Stem Cells (iPSCs) and remarkably; Mesenchymal Stem cells (MSCs). The first two; as the "gold standards" of plutipotency and differentiation and the third for its regenerative and trophic support properties [2]. All these virtues can be enhanced through CRISPR/Cas9 technology; -increased proliferation [3]; directed differentiation towards specific lineages [4]; major production of trophic factors- in such a way that it is begun to direct the way in which the regenerative process is given; intentionally.

Beyond Regenerative Medicine: Leading to SelfRepair

The rapid evolution of the CRISPR systems; allow to idealize in the not too distant future; ways of being able to heal the damaged tissue in vivo; in order to restore complete organs functionality; enabling to alleviate the problems of the shortage of organs available in the health centers; for transplants. However; currently most research groups are in the standardization of methods to enhance regenerative capacities. A few others are already beginning to demonstrate the precise manipulation of stem cells into the repair of complex tissues. One of the fundamental elements is to be able to adequately obtain the damaged cell population in the tissue to be repaired. The group of Furuhata et al. [4] promotes de differentiation of MSCs towards adipocyte-like cells in vivo; through a dCas9-based transcription system; converted via single-gene activation. These works demonstrate a remarkable manipulation of endogenous genes that could replenished the damaged adipocyte population using the MSCs from the niche. Likewise; this precise-editing example could be applied to any stem population where genes involved in differentiation and maturation are identified.

On the other hand; Stem Cells release factors such as cytokines; growth factors; interleukins; antioxidants; chaperone molecules; exosomes; microRNAs; also known as the secretome [5]. Interestingly; MSCs has been associated to release neurotrophic factors in a similar way as Neural Stem Cells (NSCs) in the Central Nervous System (CNS) and performed enhanced neuronal and astrocytic survival and differentiation [6]. Therefore; the manipulation of the secretome could be key for promote precise therapeutic approaches within the CNS. For example; Raikwar et al. [7]; discovered a proinflammatory molecule; Glia maturation factor (GMF); that is expressed in the reactive glial cells surrounding the amyloid plaques in Alzheimer Disease (AD) human brains. They developed lentiviral-vectors based in SpCas9; directed to GMF; suggesting that the in vivo 
targeting (gene-editing) could lead to a novel therapy to counteract the inflammation existing in AD.

Another interesting approach might be; the use of human MSCs that can sense the presence of GMF and that will release neurotrophic factors; promoting a self-repair of the reactive glia present not only in AD; but also, in Parkinson's Disease (PD) and other neurodegenerative diseases. This through the construction of an inducible synthetic circuit; using modern assembly techniques as BioBricks; Gibson or Golden gate [8].

\section{Perspectives and Conclusion}

Several areas have emerged in search of improving the regenerative process in mammals; recent literature indicates that regenerative medicine will make significant progress by controlling properties in situ; teaching the tissue to regenerate itself or by an impulse generated by manipulating the genetic program of resident Stem Cells. In addition; the growing technology advances in scaffolds production; assisted by 3D printing; could elicit the formation of tissue in vitro that resembles key human properties; being suitable for drug discovery; disease modeling or tissue transplant. On the other hand; the refinement of organoids through CRISPR/Cas9 systems; may establish the guideline for directing the regenerative process and in a safer way; before being tested directly on patients. In summary; over the next decade; great achievements will be made by directing the regenerative processes; through modern gene-editing technologies as CRISPR systems.

\section{Conflicts of Interest}

The authors state that there are no conflicts of interest.

\section{Acknowledgement}

This work was supported by funds from CONACyT (271307); Mexico.

\section{References}

1. Zhang Z, Zhang Y, Gao F, Han S, Cheah KS, et al. (2017) CRISPR/Cas9 Genome-Editing System in Human Stem Cells: Current Status and Future Prospects. Mol Ther Nucleic Acids 9: 230-241.

2. Trohatou O, Roubelakis MG (2017) Mesenchymal Stem/Stromal Cells in Regenerative Medicine: Past, Present, and Future. Cell Reprogram 19(4): 217-224.

3. Bressan RB, Dewari PS, Kalantzaki M, Gangoso E, Matjusaitis M, et al. (2017) Efficient CRISPR/Cas9-assisted gene targeting enables rapid and precise genetic manipulation of mammalian neural stem cells. Development 144(4): 635-648.

4. Furuhata Y, Nihongaki Y, Sato M, Yoshimoto K, et al. (2017) Control of Adipogenic Differentiation in Mesenchymal Stem Cells via Endogenous Gene Activation Using CRISPR-Cas9. ACS Synth Biol 6(12): 2191-2197.

5. Vizoso FJ, et al. (2017) Mesenchymal Stem Cell Secretome: Toward Cell-Free Therapeutic Strategies in Regenerative Medicine. Int J Mol Sci 18(9)

6. Teixeira FG, Panchalingam KM, Assunção-Silva R, Serra SC, Mendes-Pinheiro B, et al. (2016) Modulation of the Mesenchymal Stem Cell Secretome Using Computer-Controlled Bioreactors: Impact on Neuronal Cell Proliferation, Survival and Differentiation. Sci Rep 6: 27791.

7. Raikwar SP, Thangavel R, Dubova I, Selvakumar GP, Ahmed ME, et al. (2018) Targeted Gene Editing of Glia Maturation Factor in Microglia: a Novel Alzheimer's Disease Therapeutic Target. Mol Neurobiol

8. Ellis T, Adie T, Baldwin GS (2011) DNA assembly for synthetic biology: from parts to pathways and beyond. Integr Biol (Camb) 3(2): 109-118.

Your next submission with Juniper Publishers will reach you the below assets

- Quality Editorial service

- Swift Peer Review

- Reprints availability

- E-prints Service

- Manuscript Podcast for convenient understanding

- Global attainment for your research

- Manuscript accessibility in different formats

(Pdf, E-pub, Full Text, Audio)

- Unceasing customer service

Track the below URL for one-step submission https://juniperpublishers.com/online-submission.php 